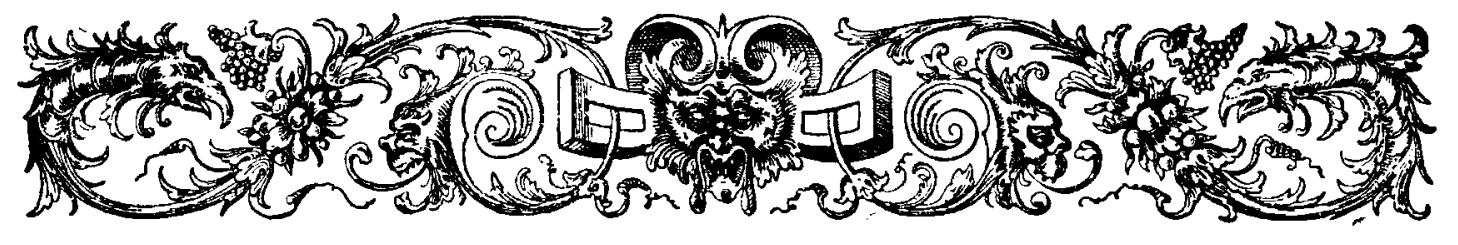

\title{
Verdwenen Rotterdamsche Schilderijen
}

DOOR

\author{
DR. E. WIERSUM.
}

I.

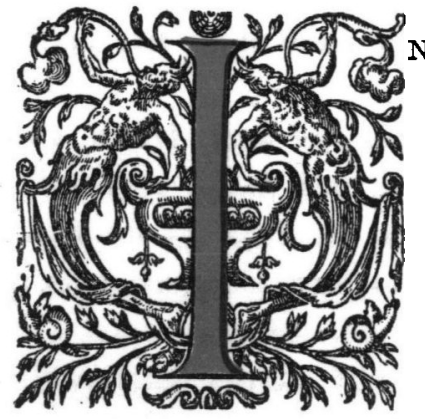

N $1622 / 23$ werd te Rotterdam een nieuwe St. Joris-doelen gebouwd. Ter linkerzijde van den ingang van dat sierlijke gebouw bevond zich de ruime Schutterszaal, later Burgerzaal geheeten, met vier ramen aan de straat. Behalve een menigte beelden en geschilderdeglazen bevatte deze zaal een aantal schilderijen: „Acht schilderijen met de beeldtenissen van verschillende hoplieden en vạandrigs de inhaling van den Marquis SPINola voorstellende, waren in deze zaal opgehangen. Op de galerij van het voorportaal hingen twee stalen voetbogen, en daartusschen eene groote schilderij, met drie en twintig ten deele aan den disch gezeten beelden, doorgaans gehouden voor het werk van LIEVE (LUDOLF) DE JONG, dien schilder als majoor der stad, te midden der toenmalige kolonellen enz., voorstellende; voorts zag men er nog zes andere schilderstukken allen met beelden in krijgsgewaad" ').

De geheele $\mathrm{I} 7 \mathrm{de}$ eeuw door en ook in het begin van de $18 \mathrm{de}$ eeuw bleven deze schilderijen, zestien in getal, op dezelfde plaats hangen, zooals uit de boedelinventarissen bij elke nieuwe verhuring van den Doelen blijkt.

In den inventaris van 1714 worden opgegeven:

"In $t$ voorhuys: alle de schuttersschilderien, Op de princesaal: alle de schilderijen.

1) VAN REYN, Geschiedkundige beschrijving der stad Rotterdam, II bl. 183. 


\section{In dien van 1770:}

In de provoostkamer: I schilderij,

Op de voorzaal: 9 schilderijen,

In het voorhuys: 7 schilderijen.

Of evenwel omstreeks dezen tijd bij een schoonmaak meteen niet een groote opruiming is gehouden? Zeker is, dat na 1770 nooit meer sprake is van zestien schilderijen. Waarschijnlijk zijn reeds toen de meeste, zoo niet van de hand gedaan, dan toch als oude rommel op zolder gezet.

In het begin der I 1 de eeuw waren slechts eenige dezer schilderijen nog aanwezig. Toen in September I 804 het Genootschap „Hierdoor tot Hooger" zijn nieuwe woning in den Oppert had betrokken, werd het Bestuur door den schilder MuYs opmerkzaam gemaakt op de schilderijen in den Stads Doelen voorhanden, voornamelijk op het schuttersstuk van LUDOLF DE JONGH en nog drie of vier andere, die als tooi voor het nieuwe vergaderlokaal zouden kunnen dienen.

Het Bestuur haastte zich, om ze daartoe in bruikleen te vragen en het Stadsbestuur verleende autorisatie om ze over te brengen; doch alleen het schil. derij van DE JONGH bleek ten slotte geschikt. Dit stuk werd door het Stadsbestuur echter gaarne afgestaan.

Wel is waar verzette de kasteleines van den Doelen, de wed. HERN, zich tegen de verwijdering van het schilderij; doch nadat zij een flinke aanmaning had gekregen, werd het naar den Oppert overgebracht, en daar, na door den corrector MUYS te zijn schoongemaakt, in de groote benedenzaal opgehangen ${ }^{1}$ ).

De drie of vier andere schuttersstukken, die in ontredderden staat verkeerden, schijnen in den Doelen te zijn achtergebleven. Wel werden Bestuurders van "Hierdoor tot Hooger" gemachtigd om ook deze af te halen, doch waarschijnlijk hebben zij hun neus er voor opgetrokken en ze rustig gelaten, waar ze waren.

Eén schilderstuk wordt in 1812 op last van Fabriekmeesteren nog uit den Doelen overgebracht naar de chassinettenkast in de Groote kerk ${ }^{2}$ ).

Wat er toen nog over was, zal in $182 \mathrm{I}$, bij het afbreken van het voorgebouw van den Doelen, zwervende zijn geworden. VAN REYN zegt, dat in I832 nog enkele bewaard waren en tevens, dat op de vlieringen van het gerechtsgebouw oude schilderijen, zoo van het schuttersgilde als van andere gilden, berustten ${ }^{3}$ ).

1) Catalogus der Kronieken en Beschrijvingen nr. 9I, IId.

Notulen van het Genootschap "Hierdoor tot Hooger".

De Oorsprong der Academie van Beeldende Kunsten. WiJT en Zonen. Rotterdam Igoo, bl. 28.

2) Notulen van Fabriekmeesteren 29 Oct. 1812 .

3) VAN REYN. bl. 183 en 187.

Over den treurigen toestand van de schilderijen van het Wijnkoopersgilde, die daar op den zolder lagen, zie men een paar brieven van 1836 in het Archief van dat gilde en HaverkorN van RIJsEWIJk, Het Museum Boijmans. bl, I4. 
En het laatste bericht, dat wij hebben, is van 1842 . Het is van veel belang; omdat er uit blijkt, dat niet alleen toen nog eenige dier kapitale schuttersstukken in wezen waren, maar ook dat zij, althans ten deele, nog in goeden toestand verkeerden. „Bij ons in de timmermanswinkel”, zoo rapporteert in dat jaar een ambtenaar ter fabricage, "staat een zeer groot hout schilderij, voorstellende eenige kapiteinen van de wacht, levensgroot en fraai geschilderd, ook nog eenige andere dito's in de woning van den Heer BRAMBACHT bewaard"').

Daar de heer BRAMBACHT, boekhouder bij de fabricage, in het Timmerhuis woonde, zullen deze schilderijen, nadat ze uit den Doelen naar het Timmerhuis waren overgebracht, onder zijn speciale hoede zijn gesteld.

$\mathrm{Na}$ dien tijd evenwel zijn ze spoorloos verdwenen.

\section{II.}

In 1690 werd het gebouw van den St. Joris-doelen te Rotterdam aan de achterzijde vergroot. In hoofdzaak volgens de plannen van den bouwkundige JAN DE VOU werd toen, met andere vertrekken, de ruime zaal aangebouwd, die naar hare bestemming den naam ontving van Krijgsraadskamer. De leden van den krijgsraad, de officieren van de schutterij, zorgden zelf voor het aankleeden van de zaal. „Den 30 September (I697)”, zoo luidt de resolutie van Burgemeesteren van dien datum, "hebben gedeputeerden van de Edele Manhafte Heeren van de Krij(g)sraad gecommuniceert derselver resolutie aen de heeren Burgemeesteren : Namentlyck dat sij, met permissie van Haar Edele Groot Achtbaren, hadden geresolveert, op haare eygen kosten, de Nieuwe Zaal in deses Stadts Doele met haare portraiten levensgroot historischewijs te laten beschilderen en dienvolgende versogten, dat haar Edele Groot Achtbaren hetzelve beliefden te consenteren en die ordere te stellen, dat de gemelte zaal daartoe wierde geapproprieert, in dier voegen, dat de muer onder ter hooghte van drie en vier voet wierde beschoten ofte gelambriseert, en voortz de muer met behoorlijcke ramen met doeck, bequaem om te kunnen beschildert werden, voorsien. Waarop gedelibereert zijnde, hebben de Heeren in het gemelte versoeck geconsenteert, dat de bovengemelte heeren van de $\mathrm{Krij}(\mathrm{g})$ sraad de voorsegde zaal op haar eygen kosten sullen mogen laten beschilderen, alsmede geaccordeert, dat op stadtskosten de gemelte zaal daartoe sal werden geapproprieert met deselve te beschieten, soo met plancken als doeck, sooals bevonden sal werden te behooren".

Onder "historischewijs" verstonden de heeren: uitgedost in Romeinsch gewaad. Niet lang duurde het, of hunne aldus geconterfeite beeltenissen, waar-

\footnotetext{
1) Catalogus der Kronieken en Beschrijvingen nr. 9x, IIe.
} 
schijnlijk levensgroot en ten voeten uit, prijkten aan de wanden. Nauwelijks twee jaar na hun verzoek was de wandschildering voltooid en beijverden Burgemeesteren zich om deze voor schadelijke invloeden van licht en vuur te vrijwaren.

"In deliberatie geleyt sijnde, is goet gevonden ende verstaen, dat tot conservatie van de groote schilderij op de nieuwe zaal in den Doele door de heeren Fabriekmeesteren die voorsieninge sal werden gedaan, dat eenige blinde en gordijne, soo voor de stercke lugt als het vier, werden gemaakt"1). Zoo resolveerden Burgemeesteren den 13 November 1699.

De wanden van de nieuwe zaal waren nu wel is waar in orde, doch het plafond moest nog geschilderd worden. En dat nam het Stadsbestuur nu zelf voor zijne rekening:

„Volgens resolutie van de Vroetschap"; besteedden I6 November I699 „de heeren Burgemeesteren, Fabriekmeesteren met adjunctie van de heeren VAN HEEL en SteEnlaCK, daartoe op den 16 October 1699 gequalificeert, het schilderen van de solderinge op de nieuwe zaal in den Doele aen de ondergeschreven personen op de volgende wijse:

ROMEYN DE HOOGE heeft aengenomen het schetze en selver in couleuren te brengen de gansche schilderij, uytgesondert het perspectyff in het middelste rond, hetwelck geresolveert is te laten doen door JAN DE Vouw in daghgelt, waarvoor, alsmede voor de teyckeninge reetz gemaackt, den voorsegden ROMEYN is toegeleyt een oxhooft franse wijn en voor defroyement tien gulden daeghs, soo langh als hij achter den andere aen de gemelte schilderije sal werken, sonder voor gaen off komen alsmede eenige reyskosten te declareren, mitz dat hij sorge draege, voor sooveel in hem is, dat de gemelte teyckeninge in 't net geschildert en in allen dele voldaen is vóór primo April I700 2).

Wijders is met MOULIJN geaccordeert, dat hij de gansche soldering de schilderij in het rond, alsmede in de koupel, alles volgens de daarvan gemaackte teykening in 't net sal schilderen, hetwelck alles wel uyttevoeren hij MouLIJN heeft aengenomen voor de somme van vijffhondert gulden sonder yetwes meer te mogen declareren en dat het werck I April I700 sal sijn voltoyt ${ }^{3}$ ).

Zoo was nu in 1700 de groote zaal geheel klaar en ,het schilderwerck t eenemael voltrocken". Tot tevredenheid van de schutterofficieren, op wier ver-

1) De hiergenoemde gordijnen waren raamgordijnen. Later worden ook nog gordijnen vóór de schilderijen gehangen. In den inventaris van $\mathrm{I}_{74}$ worden deze met name genoemd: "twee gardinen groot voor de schilderien"; in 1770 is er nog neen dwars dito" bij.

2) Afgedrukt in „Rotterdam geschetst in zijne voornaamste gebouwen enz.", bl. 59, noot 5 .

17 Aug. I700 werd aan ROMEYN DE HOOGE 630 gulden betaald "over de ocupaetien gehad in 43 dagen in de ordonnantie aan de Sael van den Doelle en voor het schilderen van lambrisornamenten aldaer". Thesauriers. rekening $5700 \mathrm{nr}$. 543. Zie voor het loon van DE VOU Rott. Historiebl. III 726.

3) 1699 staat er bij vergissing. 
zoek, ter completeering van het ameublement, nog twee groote spiegels in de zaal geplaatst werden.

En voor het onderhoud werd behoorlijk zorg gedragen. In I 780 nog werden Burgemeesteren en Fabriekmeesteren geautoriseerd om de schilderijen in de Groote Krijgsraadzaal te doen schoonmaken en vernissen, „mits betragtende het welzijn der schilderijen en, zoo veel mogelijk is, het interest dezer stad" ${ }^{1}$ ).

Ruim een eeuw lang bleef deze zaal ongeschonden bewaard. In I 82 I evenwel, bij het bouwen van het Paleis van Justitie op de plaats van het voorgebouw van den Doelen, moest ook de Krijgsraadzaal het ontgelden.

$\mathrm{Zij}$ werd ingericht als gehoorzaal en de betimmering weggenomen. Met deze verdwenen ook de schilderijen; want eenige jaren later, in 1832 , spreekt VAN REYN reeds van de zaal als „voormaals prachtig beschilderd".

De vraag is, waar zijn deze Rotterdamsche schuttersstukken gebleven? In het Museum Boijmans is slechts één stuk van r604 aanwezig ${ }^{2}$ ). Een ander, het kapitale stuk van LUDOLF DE JONGH, werd in 1849 door het Stadsbestuur aan het Bestuur van "Hierdoor tot Hooger" weer opgevraagd en ging helaas bij den brand van het Museum Boijmans in 1864 te gronde.

Dat is alles wat we weten van de losse schilderijen. Van de vaste, de wand- en plafondschilderingen in de Krijgsraadzaal, is nog minder bekend. Volgens MEES ${ }^{8}$ ) moesten ze in $182 \mathrm{I}$ plaats maken voor een papieren behangsel. Wil dit zeggen, dat ze toen opgeruimd zijn, dan wel bestaat nog de mogelijkheid, dat ze te eeniger tijd van achter het behang weer voor den dag kunnen komen? Wij weten het niet. Wel kunnen we met zekerheid zeggen, dat op vlieringen en zolders, in kasten en kelders van Raadhuis en Kerk, van Doelen en Gerechtsgebouw (Oud en Nieuw) ${ }^{4}$ ), van Timmerhuis en Oude-Vrouwenhuis thans niets meer te vinden is. De directeur van het Museum Boijmans en ik hebben alles afgezocht; doch onze moeizame tochten hebben niet het minste resultaat gehad. Wie kan ons een ander spoor wijzen?

1) Resolutien van de Vroedschap rakende de fabricage 28 Maart 1780 .

2) Zie hierover F. Schmidt Degrmer, Jaarverslag I913 van het Museum Boymans.

3) Rotterdam geschetst in zijn voornaamste gebouwen enz. bl. 60.

4) De president der Arr. Rechtbank, Mr. J. H. vaN Meurs, had ons reeds verzekerd, dat in het nieuwe - gerechtsgebouw niets aanwezig was, doch verzocht ons ten overvloede, ons daarvan zelf te komen overtuigen. 